\title{
In situ Polymerized Wood Polymer Composite: Effect of Additives and Nanoclay on the Thermal and Mechanical Properties
}

\author{
Rashmi R Devi, Tarun K Maji* \\ Department of Chemical Sciences, Tezpur University, Napaam-784028, Assam, India
}

Received: April 2, 2012; Revised: January 29, 2013

\begin{abstract}
This study concerns the preparation and characterization of wood polymer nanocomposites based on impregnation of styrene acrylonitrile co-polymer-nanoclay intercalating system in presence of glycidyl methacrylate (GMA), a cross linking agent, and vinyl trichloro silane (VTCS) as additives into Simul (Bombex ceiba, L.), a soft wood. The effect of nanoclay and VTCS on the properties of the resultant wood polymer nanocomposites (WPNC) has been evaluated. FTIR spectroscopy shows the interaction among wood, polymers, GMA, nanoclay and VTCS. The penetration of polymer and nanoclay into the wood cell wall is supported by SEM study. The distribution of nanoclay in the SAN polymer matrix present within the wood cell wall has been evidenced by TEM study. TGA results show an improvement in the thermostability of the resultant composites. The inclusion of VTCS enhances the self extinguishing behaviour of the WPNC as revealed by limiting oxygen index (LOI) test. Due to treatment, the resultant WPNC exhibits an improvement in all the properties like water repellancy, dimensional stability, hardness, flexural, tensile and thermal stability compared to untreated wood.
\end{abstract}

Keywords: co-polymers, flame retardance, mechanical properties, organoclay, thermogravimetric analysis, transmission electron microscopy

\section{Introduction}

Simul (Bombex ceiba, L.), a soft wood, is not useful for constructional purposes due to its poor dimensional stability and mechanical properties. However, these properties can be enhanced through formation of composites. Woodpolymer composites (WPC), prepared by the impregnation of vinyl monomers followed by in situ polymerization by either $\gamma$-radiation or catalyst heat treatment, generally exhibit enhanced strength, improved thermal properties and dimensional stability, and resistance to biodeterioration ${ }^{1-4}$. Impregnation of woods with vinyl or acrylic monomers shows less dimensional stability in the presence of moisture ${ }^{5}$. Incorporation of cross linking material in wood sample provides better dimensional stability to the wood polymer composite $^{6,7}$.

Applications of nanotechnology to wood have been performed in recent years, for the conservation and restoration of the world's cultural heritage. Impregnation of melamine urea formaldehyde (MUF) and phenol formaldehyde (PF) prepolymer containing hydrophobic nanofillers into wood has improved significantly surface hardness, modulus of elasticity and water repellency ${ }^{8,9}$.

It is well documented that the loading of clay into polymer enhances mechanical, barrier and flame retardant properties. Most authors conclude that the clay has to be used in combination with other additives in order to meet fire resistance requirements ${ }^{10}$.

Increased efforts to expand the use of wood products in institutional and commercial structures may require wood to be treated with fire retardants. Flame retardancy is generally

*e-mail: tkm@tezu.ernet.in imparted to woods by impregnating phosphate, silica, boron type compounds into wood ${ }^{11}$. The composites impregnated with bis (2-chloroethyl) vinyl phosphonate have shown maximum improvement in thermal stability. It has been reported that the improvement in fire retardancy of wood has been obtained on treatment with thio-urea-formaldehyde resin and orthophosphoric acid ${ }^{12}$.

Although the use of halogenated compounds as flame retardant agents are gradually diminishing due to environmental problems yet these are still in use owing to various advantages like low cost, miscibility and low reduction in physical/mechanical properties of the flame retardant system. The advantage of using reactive flame retardant monomer compared to other flame retardant additives is that they can be used at relatively lower concentration. Since they are incorporated in the polymer structure, they can improve the compatibility with the polymer as well as reduce the migration of flame retardant agent to the surface.

The addition of a relatively low amount of silicon-based compounds (silicones, silicas, organosilanes, silsequioxanes and silicates) to polymers has been reported to substantially improve their flame retardancy ${ }^{13}$. Silane monomers are generally preferred over polysiloxane compounds for impregnation of wood. It can easily penetrate into the cell wall of wood, polymerize in situ and thus reduces the leaching during outdoor use. Wood treated with monomeric alkoxysilane shows improved cell wall bulking, dimensional stability, moisture uptake and durability compared to wood treated with oligomeric alkoxysilane ${ }^{14}$. Organically modified 
montmorillonite (OMT) and silica modified with 3-amino propyl trimethoxysilane enhance the flame retardant property when incorporated in ABS nanocomposites due to the synergistic effect between OMT and modified silica ${ }^{15}$.

The present paper is a continuation of the work originated by Devi and Maji ${ }^{16}$. The impregnation of vinyl trichlorosilane as an additive along with nanoclay and SAN polymer into wood and its effect on various properties like mechanical, flame retardancy, thermal stability, water absorption, dimensional stability (ASE), hardness have been investigated.

\section{Experimental}

\subsection{Material}

Simul wood (Bombex ceiba L.) was collected from local area Tezpur, India. Styrene obtained from E. Merck (Mumbai, India), was purified by following standard procedure. Acrylonitrile, Glycidyl methacrylate (GMA) and 2, 2'-azo bis isobutyronitrile (AIBN) obtained from Merck (Germany) were used as received. Organically modified nanoclay (Nanomer, surface modified by 15-35 wt $\%$ octadecylamine and 0.5-5 wt\% amino propyl triethoxy silane) and vinyl trichloro silane were purchased from Sigma-Aldrich (USA) and Alfa Aesar, India respectively. All other chemicals used were of analytical grade.

\subsection{Sample preparation}

The simul wood samples used for the study were prepared from defect free wood, cut into blocks of $2.5 \mathrm{~cm} \times 1 \mathrm{~cm} \times 2.5 \mathrm{~cm}$ for dimensional stability, water uptake and hardness tests.

For tensile strength measurement, the samples were prepared according to ASTM D 638. The samples were cut into $10 \mathrm{~cm} \times 0.5 \mathrm{~cm} \times 2 \mathrm{~cm}$ using standard method.

For bending strength measurement, the blocks were cut into dimension of $1 \mathrm{~cm} \times 1 \mathrm{~cm} \times 10 \mathrm{~cm}$ (radial $\times$ tangential $\times$ longitudinal) according to ASTM D 790 method.

\subsection{Preparation of Styrene acrylonitrile co-polymer}

The styrene acrylonitrile co-polymer was prepared by taking monomer of styrene and acrylonitrile in the molar ratio of 2:3, as suggested by Liu et al. ${ }^{17}$. The polymerization was done by bulk polymerization technique in presence of $0.05 \mathrm{phr}$ of AIBN in an oil bath at $70-80{ }^{\circ} \mathrm{C}$ for approximately 30 minutes. After the polymerization was over, the reaction was immediately stopped. The mixture, referred to as SAN prepolymer, was poured into a closed flask and cool down at ambient temperature. The flow out time (at $30^{\circ} \mathrm{C}$ ) for different prepared batches was almost similar as judged by Ubbelohde Viscometer.

\subsection{Preparation of Wood/SAN/MMT/VTCS nanocomposites}

In the preparation of wood polymer nanocomposites based on impregnation of polymer /nanoclay all the preliminary steps were followed as reported earlier ${ }^{2}$. Here the dispersion of SAN prepolymer-organically modified nanoclay with GMA, VTCS and initiator, or dispersion of SAN prepolymer, with GMA and initiator, or that of SAN prepolymer and initiator was added from a dropping funnel to completely immerse the wood samples. The samples were then kept in the chamber at room temperature for another 4 hours after attaining atmospheric pressure. This is the minimum time to get maximum polymer loading. After impregnation, samples were taken out of the chamber and excess chemicals were wiped from wood surfaces, the samples were then wrapped in aluminium foil and cured at $90{ }^{\circ} \mathrm{C}$ for 24 hours in an oven. This was followed by drying at $105^{\circ} \mathrm{C}$ for another 24 hours. The cured samples were then soxhlet extracted using chloroform to remove homo polymers, if any, formed during polymerization. Finally the samples were dried and the dimensions were measured by using slide caliper and weights were taken. The compositions are summarized in the Table 1.

\subsection{Weight percent gain}

Weight percent gain (WPG) after polymer loading was calculated according to formula as reported in our previous study ${ }^{2}$.

\subsection{Volume increase (\%) after impregnation}

Percentage volume increase after curing of wood samples after polymer loading was calculated according to formula as reported in our previous study ${ }^{2}$.

Table 1. Composition of untreated and treated wood.

\begin{tabular}{|c|c|c|c|c|c|}
\hline Sample code* & SAN & THF(weight $\%, v / v$ ) & GMA(weight $\%, v / v)$ & Nanoclay(weight $\%, w / v)$ & VTCS(weight $\%, v / v$ ) \\
\hline W & - & - & 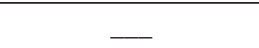 & 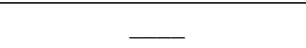 & 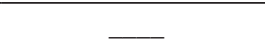 \\
\hline S & 100 & 20 & - & - & 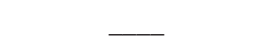 \\
\hline S/G5 & 100 & 20 & 5 & ב & 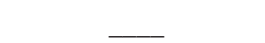 \\
\hline $\mathrm{S} / \mathrm{G} 5 / \mathrm{N} 1$ & 100 & 20 & 5 & 1.0 & 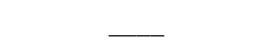 \\
\hline $\mathrm{S} / \mathrm{G} 5 / \mathrm{N} 1 / \mathrm{V} 0.5$ & 100 & 20 & 5 & 1.0 & 0.5 \\
\hline S/G5/N1/V1 & 100 & 20 & 5 & 1.0 & 1.0 \\
\hline $\mathrm{S} / \mathrm{G} 5 / \mathrm{N} 1 / \mathrm{V} 2$ & 100 & 20 & 5 & 1.0 & 2.0 \\
\hline S/G5/V2 & 100 & 20 & 5 & 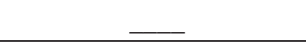 & 2.0 \\
\hline
\end{tabular}

*Untreated wood (W); styrene acrylonitrile copolymer (SAN); tetrahydrofuran(THF); glycidyl methacrylate(GMA), nanoclay, vinyl trichloro silane were designated as $\mathrm{W}, \mathrm{S}, \mathrm{T}, \mathrm{G}, \mathrm{N}$ and $\mathrm{V}$ respectively. 


\subsection{Hardness}

The hardness of the samples was measured according to ASTM D2240 method using a durometer (model RR12) and expressed as shore D hardness.

\subsection{FTIR study}

The treated and untreated samples were grounded and FTIR spectra were recorded by using a $\mathrm{KBr}$ pellet in a Nicolet (model Impact 410) FTIR spectrometer.

\subsection{X-ray diffraction (XRD) study}

In order to assess the morphological properties of WPC, XRD analysis was applied. A Rigaku X-ray diffractometer (Miniflex,UK) was used where Cuk $\alpha$ radiation $(\lambda=0.154 \mathrm{~nm}$ ) was employed at a scanning rate of $1^{\circ} / \mathrm{min}$ from $2^{\circ}$ to $30^{\circ}$ of $2 \theta$.

\subsection{Morphological study}

\subsubsection{Scanning electron microscopy (SEM) study}

The interfacial bonding between the cell wall polymer, nanoclay and cross linker was examined using a scanning electron microscope (JEOL JSM-6390 LV) at an accelerated voltage of 5-15 KV. Fractured surface of some of the selected wood samples coated with platinum were used for the study.

\subsubsection{Transmission electron microscopy (TEM) study}

For the preparation of (ultra) thin as well polished section, the samples were embedded with epoxy resin according to the method of Spurr ${ }^{18}$. Ultra-thin sections (approx. $100 \mathrm{~nm}$ thick) of the transverse film surfaces were sectioned using an ultramicrotome fitted with a diamond knife. The sections were stained with $1 \%(\mathrm{w} / \mathrm{v})$ uranyl acetate for sufficient contrast. After staining, the sections were mounted on grids and examined with a JEOL JEM-2100 transmission electron microscope at an accelerating voltage of $80 \mathrm{kV}$.

\subsection{Mechanical properties}

The flexural strength of the samples was measured by UTM- HOUNSEFIELD (model H100-S), England with a cross head speed of $2 \mathrm{~mm} / \mathrm{min}$ and by calculating the modulus of elasticity (MOE) and modulus of rupture (MOR) according to ASTM D790 method.

MOR was calculated as follows:

$\mathrm{MOR}=3 \mathrm{WL} / 2 \mathrm{bd}^{2}$

where $\mathrm{W}$ is the ultimate failure load, $\mathrm{L}$ is the span between centres of support, $\mathrm{b}$ is the mean width (tangential direction) of the sample and $\mathrm{d}$ is the mean thickness (radial direction) of the sample.

The tensile strength was performed by using UTMHOUNSEFIELD (model H100-S), England with a 5-KN load cell and crosshead speed of $10 \mathrm{~mm} / \mathrm{min}$ according to ASTM D638.

\subsection{Thermogravimetric analysis}

Thermal properties of the untreated and treated wood samples were measured by using a thermogravimetric analyzer (model TA 50, Shimadzu) at a heating rate of $10^{\circ} \mathrm{C} /$ min up to $600{ }^{\circ} \mathrm{C}$ under $\mathrm{N}_{2}$ atmosphere.

\subsection{Limiting oxygen index test}

Limiting oxygen index (LOI) is defined as the minimum concentration of oxygen, expressed as percent volume, in a flowing mixture of oxygen and nitrogen that will support flaming combustion of a material initially at room temperature. It was performed according to ASTM D286377 and calculated as per formula given in our previous communication $^{19}$.

\subsection{Water uptake test}

To determine the water uptake, the Water Absorption Test of the raw wood and WPC specimens was carried out according to ASTM D 570-99, $2002^{20}$.

\subsection{Water vapor exclusion test}

Water vapor exclusion test was done by following the method as reported in the literature ${ }^{21}$.

\subsection{Dimensional stability test}

\subsubsection{Swelling in water vapor}

Samples were first dried at $105^{\circ} \mathrm{C}$ and dimensions were measured. Samples were then conditioned at $30^{\circ} \mathrm{C}$ and $65 \%$ RH. Finally, the samples were placed in a chamber were $\mathrm{RH}$ and temperature were maintained at $65 \%$ and $30{ }^{\circ} \mathrm{C}$, respectively. The dimensions were remeasured after (0.5-168 hours).

\subsubsection{Swelling in water}

Dimensions of the oven- dried samples were measured and conditioned at room temperature $\left(30^{\circ} \mathrm{C}\right)$ and $30 \%$ relative humidity. Final placement of the samples was done in distilled water and then dimensions were remeasured after different time intervals. Swelling was considered as a change in volume and calculated according to the procedure ${ }^{22}$.

\subsubsection{Anti-swelling efficiency}

The anti-swell efficiency (ASE) index was determined to evaluate dimensional stability of treated wood specimens and calculated according to the procedure described in the literature $^{21}$.

\subsection{Statistical analysis}

All the data for mechanical tests are expressed as means \pm SD. Results were statistically analysed using one way ANOVA (R software) followed by Tukey HSD test. Mean comparison of the results before and after UV exposure were analysed by t-test.

\section{Results and Discussion}

The conditions of impregnation to get the highest level of polymer loading were optimized by varying vacuum, monomer concentration, initiator concentration, and time of impregnation respectively. The conditions for highest polymer loading, which showed maximum improvement in properties, were as per the following. 
Vacuum $=508 \mathrm{~mm}$ of $\mathrm{Hg}, \mathrm{SAN}: \mathrm{THF}=5: 1$, GMA $=5 \mathrm{~mL}$, nanoclay $=1.0 \%(\mathrm{w} / \mathrm{v}), \mathrm{AIBN}=0.75 \%(\mathrm{w} / \mathrm{w})$ and VTCS $=0.5-2.0 \%(\mathrm{v} / \mathrm{v})$.

\subsection{Effect of variation of VTCS concentration on polymer loading (WPG, \%) and other properties}

Effect of variation of VTCS concentration on WPG (\%) and other properties are shown in Table 2. Polymer loading (WPG \%) and volume increase (\%) were found to enhance with the increase in VTCS concentration. Hardness showed a increasing trend throughout the concentration of VTCS studied. The improvement was maximum at (100:20:5:1:2) ratio of SAN: THF: GMA: nanoclay: VTCS. As expected, the addition of GMA to the SAN polymer increased the hardness23. The hardness was found to increase further when VTCS was incorporated. Improvement in hardness was due to the presence of silane group in VTCS. The treatment of radiata pine (soft wood) and black butt (hardwood) with MMA and silane improved the hardness ${ }^{24}$. The increase in volume might be due to bulking of the cell wall caused by the incorporation of chemicals. Bulking reduced the cell wall's ability to shrink and swell and thus improved dimensional stability of the wood samples21.The deposition was further improved by the cross linker GMA and VTCS which interacted with both the polymer and wood through their double bonds and polar groups.

\subsection{FTIR study}

Figure 1 shows the FTIR spectra of (a) untreated, (b) VTCS, (c) S/G5 (d) S/G5/N1, (e) S/G5/V2, and (f) $\mathrm{S} / \mathrm{G} 5 / \mathrm{N} 1 / \mathrm{V} 2$ treated wood samples. The presence of absorption bands of untreated wood (curve-a) at 3435 , $1740,1257 \mathrm{~cm}^{-1}$ were for $-\mathrm{OH}$ stretching, $\mathrm{C}=\mathrm{O}$ stretching of acetylated xylem and C-O stretching of acetyl groups respectively ${ }^{25}$. The absorption bands occurred at 2967 , $1602,1406,760,528,431 \mathrm{~cm}^{-1}$ were the characteristic peaks of $-\mathrm{CH}_{2}$ stretching vibration, $-\mathrm{C}=\mathrm{C}$ stretching vibration, $\mathrm{CH}_{2}$ deformation, $\mathrm{Si}-\mathrm{C}$ stretching, $\mathrm{SiCl}_{3}$ antisymmetric and $\mathrm{SiCl}_{3}$ symmetric stretching respectively ${ }^{26}$. S/G5 treated samples (curve-c) showed the absorption band at $3026 \mathrm{~cm}^{-1}\left(-\mathrm{CH}_{2}\right.$ stretching $), 2240 \mathrm{~cm}^{-1}(\mathrm{C} \equiv \mathrm{N}$ stretching). In the spectrum of S/G5/N1 (curve-d) treated sample, the characteristic peaks for nanoclay appeared at $3465 \mathrm{~cm}^{-1}$ (-OH stretching), $2925 \mathrm{~cm}^{-1}$ (C-H stretching),
$1620 \mathrm{~cm}^{-1}\left(\mathrm{OH}\right.$ bending) and 1030-460 $\mathrm{cm}^{-1}$ (oxide bands of metals). S/G5/V2 (curve-e) treated sample showed all the characteristic peaks of VTCS and SAN. The appearance of characteristic peaks for nanoclay, SAN, VTCS in the spectrum of S/G5/N1/V2 treated samples (curve-f) indicated the impregnation of SAN, nanoclay and VTCS into wood ${ }^{27}$. It was noteworthy that, the characteristic bands of unsaturated double bond from GMA and VTCS occurred at 1638 and $1602 \mathrm{~cm}^{-1}$. With the inclusion of VTCS, the shifting of the peak of unsaturated double bond of GMA from $1638 \mathrm{~cm}^{-1}$ to $1615 \mathrm{~cm}^{-1}$ was observed (not shown in the figure) which suggested the interaction of GMA with VTCS ${ }^{22}$.

\subsection{X-Ray diffraction study}

Figure 2 represents the X-Ray diffractograms of (a) untreated wood, (b) nanoclay and wood samples treated with (c) S/G5/N1, (d) S/G5/N1/V1 and (e) S/G5/N1/V2. The interlayer distance for nanoclay at $2 \theta=4.1^{\circ}$ was calculated and found to be $2.15 \mathrm{~nm}$. Similarly wood sample showed a peak at $2 \theta=23.05^{\circ}$ which was due to crystal plane (002) of cellulose. Wood samples treated with S/G5/N1 exhibited only the characteristic peak of cellulose. The peak for nanoclay was found to disappear. Therefore it could be

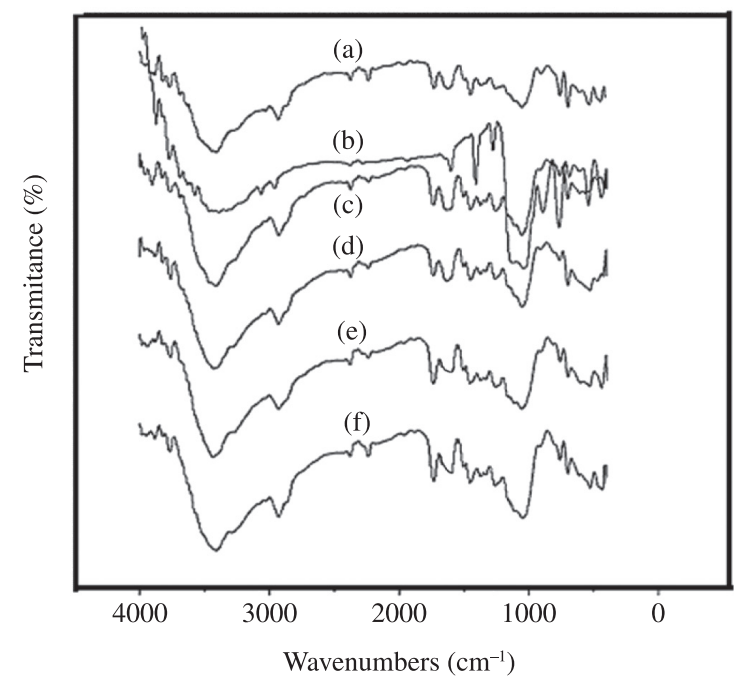

Figure 1. FTIR spectra of a) untreated wood, (b) VTCS and wood samples treated with (c) S/G5, (d) S/G5/N1, (e) S/G5/V2 and (f) $\mathrm{S} / \mathrm{G} 5 / \mathrm{N} 1 / \mathrm{V} 2$

Table 2. Effect of variation of VTCS on polymer loading (WPG \%), volume increase and hardness.

\begin{tabular}{lccc}
\hline Sample particulars & WPG $(\%)^{*}$ & Volume increase $(\%)^{*}$ & Hardness (Shore D)* $^{*}$ \\
\hline W & $-\overline{24.01( \pm 0.12)}$ & $-\overline{35.2( \pm 0.68)}$ \\
S & $36.73( \pm 0.12)$ & $3.69( \pm 0.18)$ & $42.2( \pm 0.68)$ \\
S/G5 & $51.15( \pm 1.25)$ & $4.62( \pm 0.21)$ & $44.8( \pm 0.68)$ \\
S/G5/N1 & $54.57( \pm 0.34)$ & $4.91( \pm 0.02)$ & $47.8( \pm 0.68)$ \\
S/G5/N1/V0.5 & $100.25( \pm 0.14)$ & $5.17( \pm 0.06)$ & $50.2( \pm 0.68)$ \\
S/G5/N1/V1.0 & $141.03( \pm 0.57)$ & $5.67( \pm 0.14)$ & $54.4( \pm 0.93)$ \\
S/G5/N1/V2.0 & $43.67( \pm 0.31)$ & $3.89( \pm 0.10)$ & $63.8( \pm 1.06)$ \\
S/G5/V2 & & & $46.6( \pm 0.44)$ \\
\hline
\end{tabular}

*Each value represents the average of five samples. Standard deviation in parenthesis. 


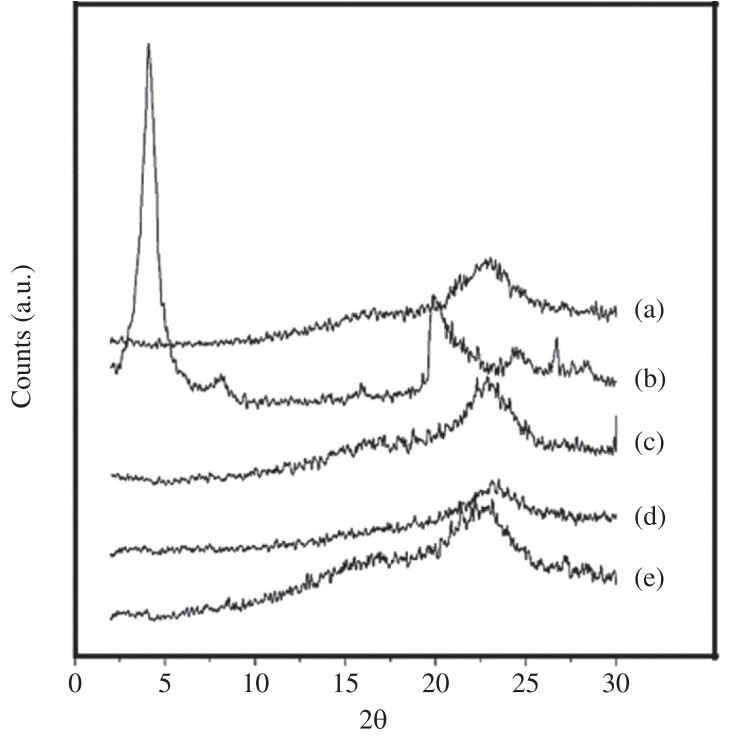

Figure 2. X-Ray diffractograms of a) untreated wood (b) nanoclay and wood samples treated with (c) S/G5/N1, (d) S/G5/N1/V1 and (e) $\mathrm{S} / \mathrm{G} 5 / \mathrm{N} 1 / \mathrm{V} 2$

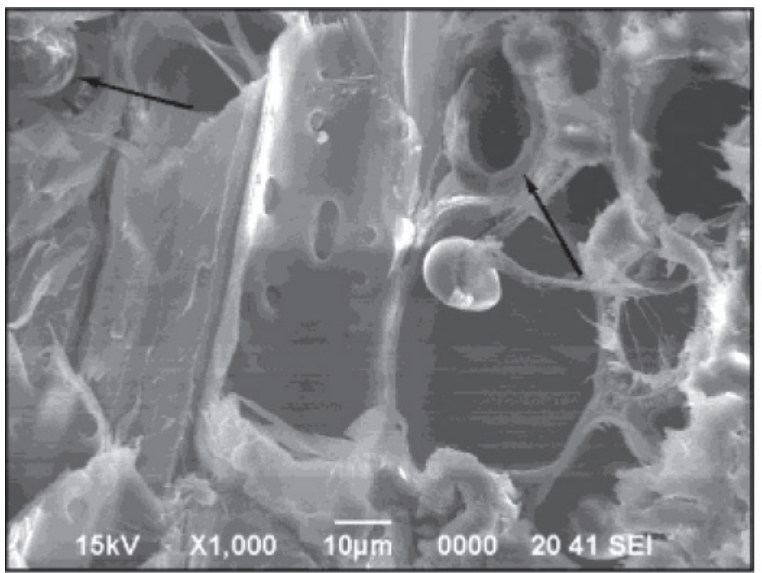

(a)

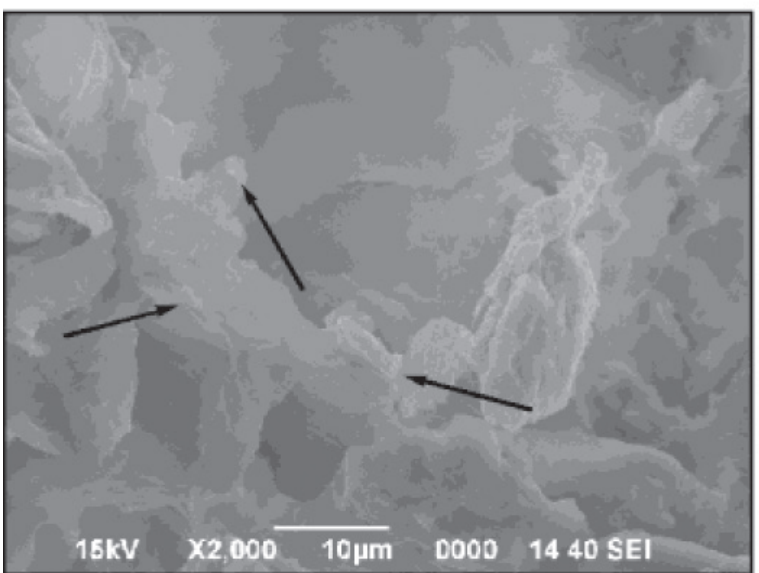

(c) said that either the interlayer distance had expanded fully or nanoclay layers became delaminated ${ }^{28}$. The addition of vinyl trichlorosilane (VTCS) to GMA/nanoclay did not alter the position of diffraction peak in wood samples. This suggested that VTCS did not affect the dispersion of nanoclay in the polymer and it had entered into the amorphous region of wood cellulose with the nanoclay.

\subsection{Morphological study}

\subsubsection{Scanning electron microscopy study}

Figure 3 shows the SEM micrographs of untreated (Figure 3a) and treated wood samples (Figure 3b-d). For untreated wood, the empty cell wall, the pit and parenchyma were seen (black arrows pointing towards cell wall and pit). In treated wood, these empty spaces were occupied by the SAN/GMA or nanoclay/GMA/SAN materials.

The adhesion between fibrous cellulose material and polymer strands enhanced due to incorporation of small amount of VTCS (black arrows pointing towards the adhesion) (Figure 3d). The increase of adhesion between fibrous cellulose material and polymer were reported by Shane et al. ${ }^{24}$. The impregnated materials were either located

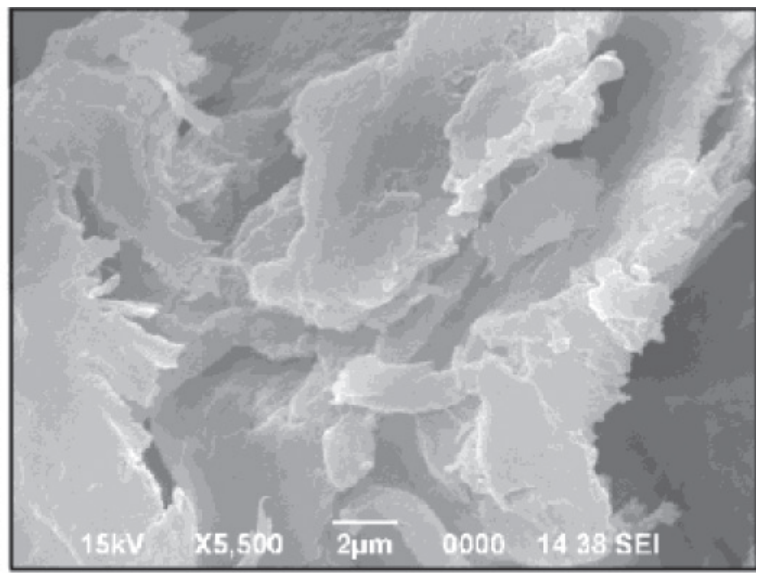

(b)

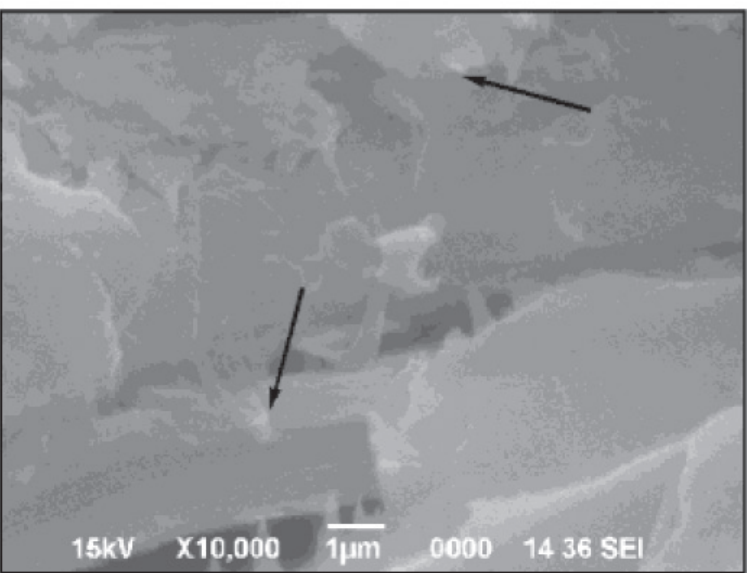

(d)

Figure 3. Scanning electron micrographs of a) untreated wood and wood samples treated with (b) S/G5, (c) S/G5/N1 and (d) S/G5/N1/V2 
in the cell walls or filled in the cell lumen. The traces of nanoclay can be detected (black arrows pointed) with scanning electron microscope as shown in Figure $3 \mathrm{c}$, d. This result also suggests that the polymer formed a strong interface with wood cell walls, accounting for the pragmatic increase in mechanical strength.

\subsubsection{Transmssion electron microscopy study}

Figure 4 represents the TEM micrographs of wood (a) untreated, and treated with (b) S/G5/N2, and (c) S/G5/N2/V2 respectively. In the case of untreated wood, the radial fracture patterns-perpendicular to the compound middle lamella was regularly arranged (Figure 4a). Moreover, no consistent orientation of the cell wall components could be distinguished. Lamellar as well as disordered and, in few cases, moderate striations perpendicular to the compound middle lamella was observed and reported ${ }^{29}$.

The dark slices for the clay silicate layers were observed in the S/G5/N1 and S/G5/N1/V2 treated wood samples (Figure 4b, c). It was evident that clays were homogeneously dispersed in the SAN polymer matrix present in the cell wall of wood. The homogeneous distribution of clay silicate layers in MUF/clay impregnated aspen wood composites was also reported by Cai et al. ${ }^{8}$.

\subsection{Mechanical properties}

Mechanical properties of WPC were evaluated by means of tensile test and flexural test (Table 3). A perceptible

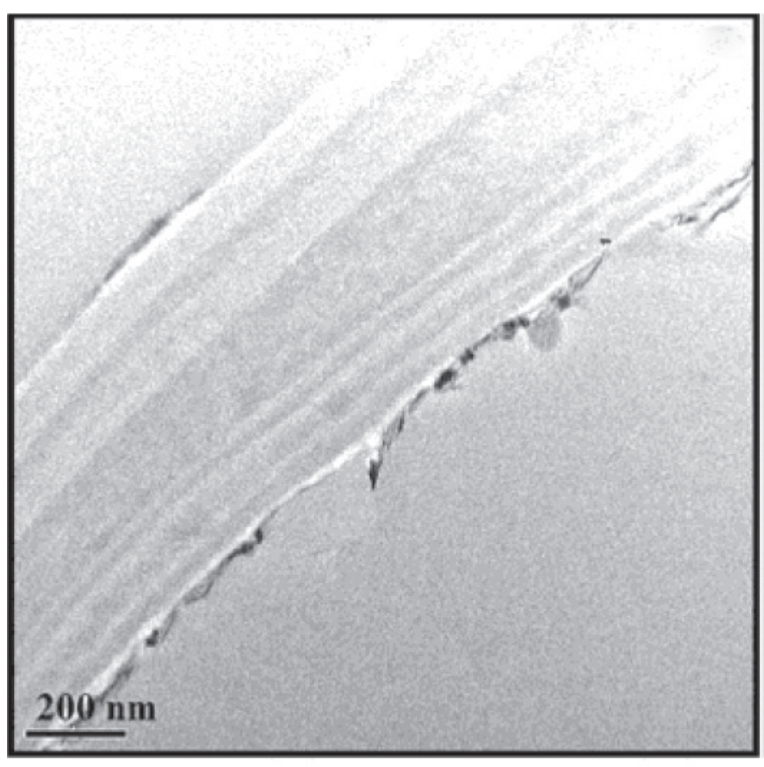

(a)

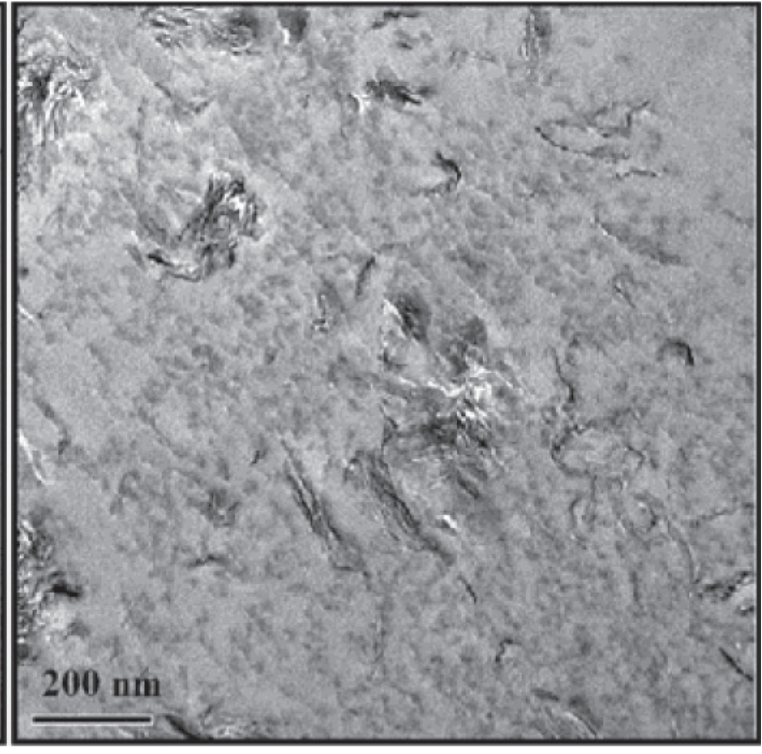

(b)

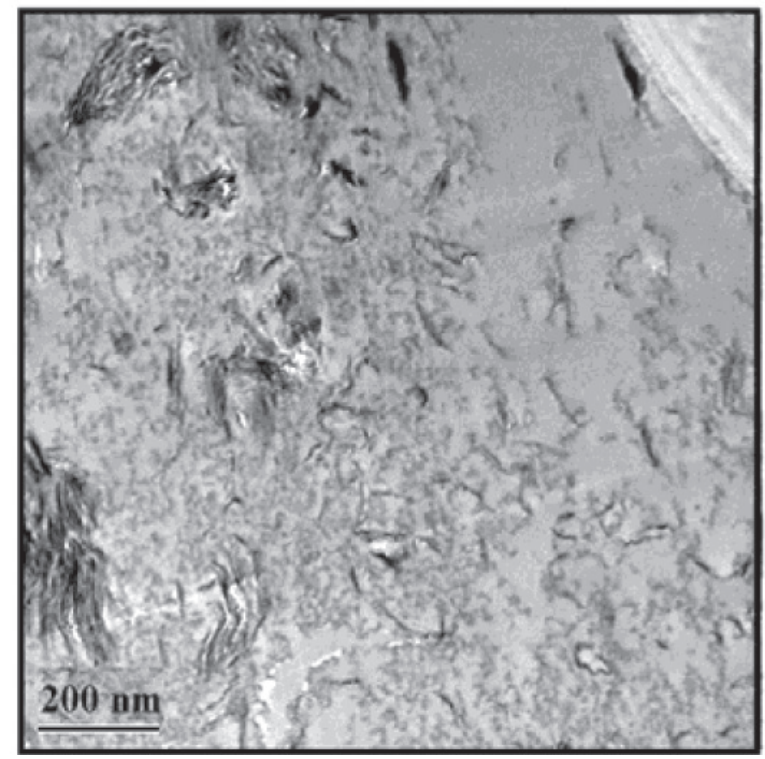

(c)

Figure 4. TEM micrographs of a) untreated wood, and wood samples treated with (b)S/G5/N1, and (c) S/G5/N1/V2 
increase in tensile strength and flexural properties were observed in the WPC prepared by the inclusion of nanoclay and VTCS. It was observed that wood treated with SAN and GMA caused an improvement in tensile strength and flexural properties. Both the tensile strength and flexural strength increased drastically when clay was added. This could be attributed to the combined effect of increasing interaction between wood and SAN by GMA and stiffening of composites due to reduction in mobility of the intercalated polymer chains. The tensile as well as flexural properties were found to improve on addition of vinyl trichloro silane and nanoclay with SAN/GMA. The improvement in properties might be due to the formation of cross links between wood and SAN by both GMA and VTCS. Silane coupling agent improved the mechanical properties of bamboo fibre filled natural rubber composites ${ }^{30}$.

\subsection{Thermogravimetric analysis}

Table 4 showed the initial decomposition temperature $\left(\mathrm{T}_{\mathrm{i}}\right)$, maximum pyrolysis temperature $\left(\mathrm{T}_{\mathrm{m}}\right)$ and residual weight $(\%)(\mathrm{RW})$ for untreated and polymer treated wood samples with or without nanoclay and vinyl trichloro silane. In all the cases, there was no significant difference in $\mathrm{T}_{\mathrm{i}}$ values except in clay and VTCS treated wood polymer composite (WPC). The $\mathrm{T}_{\mathrm{m}}$ values of clay and VTCS treated samples were more compared to those of other treated samples. RW (\%) values of wood polymer composites treated with VTCS/clay were found less compared to that of untreated wood.

Table 4 shows the temperature of decomposition $\left(\mathrm{T}_{\mathrm{D}}\right)$ values at different weight losses for different samples. $T_{D}$ values of polymer treated wood samples were observed higher than those of virgin wood samples. $T_{D}$ values increased due to incorporation of GMA.

$T_{D}$ values increased further on inclusion of nanoclay. The higher $T_{D}$ values might be due to the formation of cross linked structure by GMA. The cross linking reduced the rate of degradation of degradable components like $\mathrm{CO}$, $\mathrm{CO}_{2}$ etc. formed during decomposition. Similar findings were reported by Devi and Maji ${ }^{31}$. The presence of silicate layer acted as a barrier and hindered the diffusion of volatile decomposition products ${ }^{32}$. The degree of cross linking increased further due to the addition of VTCS and hence decreased the rate of elimination of volatile decomposed products.Limiting Oxygen Index (LOI) study

The LOI values are summarized in the Table 3.The LOI test assumed that inherently less flammable materials required greater oxygen concentrations to produce the heat necessary for the continued production of flammable volatiles and flame propagation. Wood treated with SAN/ GMA/nanoclay -VTCS system exhibited maximum flame retardancy as evident from higher LOI value. The higher

Table 3. Tensile and flexural properties of treated and untreated wood samples.

\begin{tabular}{lccccc}
\hline & \multicolumn{2}{c}{ Tensile properties* } & \multicolumn{2}{c}{ Flexural properties* } & LOI $(\%)^{*}$ \\
\cline { 2 - 6 } Sample particulars & $\begin{array}{c}\text { Tensile modulus } \\
(\mathbf{M P a})\end{array}$ & $\begin{array}{c}\text { Tensile strength } \\
(\mathbf{M P a})\end{array}$ & $\begin{array}{c}\text { Flexural modulus } \\
(\mathbf{M P a})\end{array}$ & $\begin{array}{c}\text { Flexural strength } \\
(\mathbf{M P a})\end{array}$ & \\
\hline Untreated W & $847( \pm 4.6)^{\mathrm{a}}$ & $27.96( \pm 0.7)^{\mathrm{a}}$ & $6327( \pm 24.5)^{\mathrm{a}}$ & $22.91( \pm 1.09)^{\mathrm{a}}$ & $11.1( \pm 0.05)$ \\
Treated with & & & & \\
S & $902( \pm 2.9)^{\mathrm{b}}$ & $34.41( \pm 1.3)^{\mathrm{b}}$ & $6512( \pm 42.5)^{\mathrm{b}}$ & $40.74( \pm 0.40)^{\mathrm{b}}$ & $16.0( \pm 0.03)$ \\
S/G5 & $911( \pm 2.7)^{\mathrm{c}}$ & $38.63( \pm 0.7)^{\mathrm{c}}$ & $7060( \pm 38.8)^{\mathrm{c}}$ & $50.05( \pm 1.31)^{\mathrm{c}}$ & $18.6( \pm 0.10)$ \\
S/G5/N1 & $944( \pm 2.5)^{\mathrm{d}}$ & $44.98( \pm 1.8)^{\mathrm{d}}$ & $8328( \pm 81.1)^{\mathrm{d}}$ & $58.25( \pm 0.36)^{\mathrm{d}}$ & $25.99( \pm 0.04)$ \\
S/G5/N1/V0.5 & $970( \pm 1.3)^{\mathrm{e}}$ & $47.07( \pm 0.3)^{\mathrm{e}}$ & $8580( \pm 53.0)^{\mathrm{e}}$ & $61.14( \pm 0.21)^{\mathrm{e}}$ & $26.34( \pm .24)$ \\
S/G5/N1/V1.0 & $975( \pm 3.5)^{\mathrm{f}}$ & $48.00( \pm 1.2)^{\mathrm{e}}$ & $8657 \pm(25.4)^{\mathrm{e}}$ & $62.14( \pm 0.39)^{\mathrm{e}}$ & $27.5( \pm 0.24)$ \\
S/G5/N1/V2.0 & $1177( \pm 5.8)^{\mathrm{g}}$ & $51.54( \pm 0.7)^{\mathrm{f}}$ & $8755( \pm 33.7)^{\mathrm{e}}$ & $63.24( \pm 0.30)^{\mathrm{e}}$ & $30.2( \pm 0.05)$ \\
S/G5/V2.0 & $901( \pm 3.7)^{\mathrm{b}}$ & $38.35( \pm 0.8)^{\mathrm{b}}$ & $7093( \pm 43.13)^{\mathrm{c}}$ & $45.75( \pm 0.30)^{\mathrm{g}}$ & $25.1( \pm 0.06)$ \\
\hline
\end{tabular}

*Each value represents the average value of five samples. The same letters are not significantly different at $\mathrm{p}=5 \%$. Comparisons were done within each formulation.

Table 4. Thermal analytical data for untreated and treated wood samples.

\begin{tabular}{|c|c|c|c|c|c|c|c|c|c|c|}
\hline \multirow{2}{*}{$\begin{array}{c}\text { Sample } \\
\text { particulars }\end{array}$} & \multirow{2}{*}{$\mathbf{T}_{\mathbf{i}}\left({ }^{\circ} \mathbf{C}\right)$} & \multirow{2}{*}{${ }^{\mathrm{a}} \mathbf{T}_{\mathrm{m}}\left({ }^{\circ} \mathbf{C}\right)$} & \multirow{2}{*}{${ }^{\mathrm{b}} \mathbf{T}_{\mathrm{m}}\left({ }^{\circ} \mathbf{C}\right)$} & \multicolumn{2}{|l|}{ RW (\%) } & \multicolumn{5}{|c|}{$\begin{array}{c}\text { Temperature of decomposition }\left(\mathrm{T}_{\mathrm{D}}\right) \text { in }\left({ }^{\circ} \mathrm{C}\right) \text { at } \\
\text { different weight loss }(\%)\end{array}$} \\
\hline & & & & $500\left({ }^{\circ} \mathrm{C}\right)$ & 20 & 30 & 40 & 50 & 60 & 70 \\
\hline $\mathrm{W}$ & 250 & 300 & - & 22.0 & 285 & 306 & 310 & 325 & 340 & 440 \\
\hline \multicolumn{11}{|l|}{ Treated with } \\
\hline S & 260 & 290 & 330 & 18.01 & 290 & 304 & 310 & 320 & 373 & 400 \\
\hline S/G5 & 263 & 298 & 371 & 18.38 & 300 & 321 & 343 & 380 & 408 & 420 \\
\hline S/G5/N1 & 261 & - & 368 & 18.57 & 304 & 325 & 378 & 390 & 410 & 420 \\
\hline S/G5/N1/V0.5 & 262 & 305 & 369 & 18.69 & 312 & 329 & 367 & 395 & 413 & 424 \\
\hline S/G5/N1/V1.0 & 264 & 310 & 378 & 20.68 & 320 & 340 & 375 & 400 & 417 & 430 \\
\hline S/G5/N1/V2.0 & 270 & 320 & 380 & 21.70 & 321 & 347 & 388 & 410 & 418 & 447 \\
\hline S/G5/V2.0 & 255 & 300 & 369 & 18.40 & 298 & 323 & 358 & 383 & 409 & 416 \\
\hline
\end{tabular}


the VTCS, the higher was the LOI value. Laoutid et al. reported that LOI value of vinyl bromide based copolymer increased with the increase in vinyl bromide content in the copolymer ${ }^{33}$. The flame retardancy effect appeared to originate from the clay's ability to contribute to char formation. This char layer formed an insulative layer to slow down heat transfer and retarded movement of gases to feed the flame ${ }^{34}$. The reduction in flammability in polymer layered silicate nano materials was due to the pyrolysis of the polymer and a collapse of the nanocomposite structure to form a silicate-carbon barrier that provided thermal protection to the underlying virgin polymer and as a result slowed the rate of volatilization of fue ${ }^{13}$. The enhancement in properties might be due to the synergistic effect between clay and VTCS during combustion of wood. Giudice et al. reported that wood impregnated with silicate improved the fire resistance properties ${ }^{35}$. Boonkrai et al. reported that organically modified clay and silica modified with 3-amino propyl trimethoxy silane improved the flame retardancy properties of ABS nanocomposites ${ }^{15}$.

\subsection{Water uptake study}

The results of water uptake for treated and untreated samples are shown in Figure 5. In both treated and untreated samples, water absorption increased with the increase in time of immersion.

Untreated samples absorbed more water than the treated samples. Wood samples treated with SAN copolymer decreased the water uptake throughout the studied time period due to the filling up the void volumes present in wood by the same. GMA treated wood showed lower water absorption because of the cross links formed by the interaction of double bond and glycidyl group of GMA with SAN copolymer and hydroxyl group of wood respectively ${ }^{2,23}$.

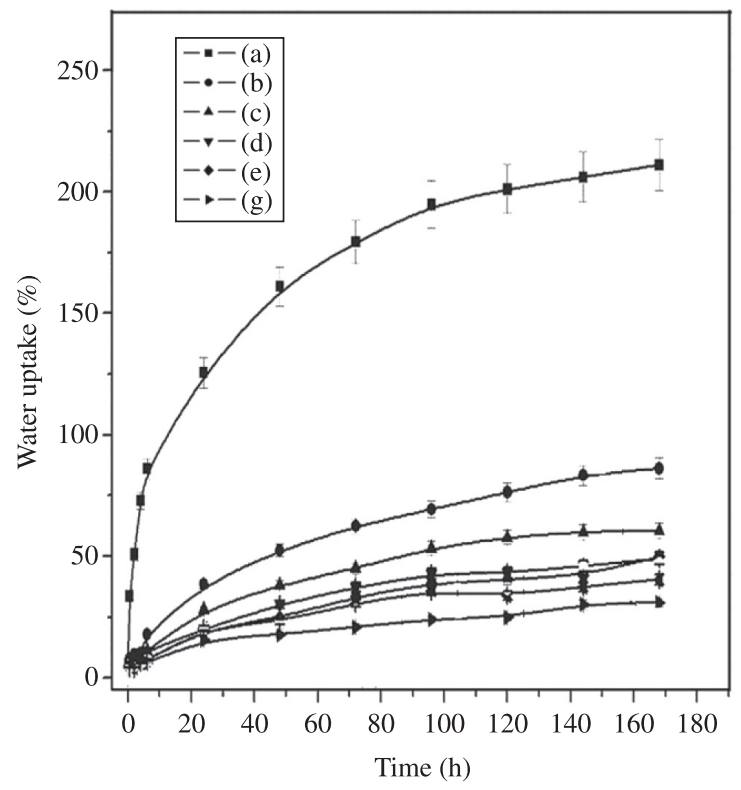

Figure 5. Water uptake $\%$ of wood samples (a) untreated and treated with (b) S, (c) S/G5, (d) S/G5/V2, (e) S/G5/N1, (f) S/G5/N1/V1 and (g) S/G5/N1/V2 at $65 \% \mathrm{RH}$ and at $30{ }^{\circ} \mathrm{C}$
The addition of nanoclay or silane further decreased the water uptake capacity. Nanoclay treated samples showed lower water absorption compared to silane treated samples. The silicate layers of the clay generated the tortuous pathway and increased the barrier property for diffusion of water within the composites $^{8}$. Wood samples treated with the combination of nanoclay and silane showed least water absorption. Nanoclay provided the tortuous path whereas silane agent enhanced the crosslinking and thus reduced the available free volume for absorption of water. The more the silane, the lower was the free volume available for absorption of water. Hence nanoclay and silane treatment decreased the water uptake capacity of SAN treated wood samples.

\subsection{Water vapor exclusion test}

In a series of water vapor exclusion study at $65 \% \mathrm{RH}$ and at $30{ }^{\circ} \mathrm{C}$ for various time periods, treated samples absorbed less water vapor than untreated samples. The trend and explanation for water vapor uptake of different samples were similar to those of samples taken for water uptake study as shown in Figure 5.

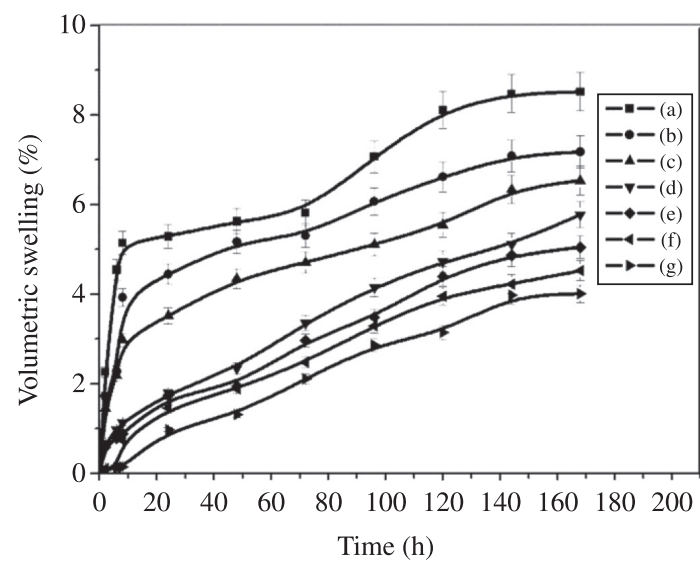

Figure 6. Volumetric swelling in water vapor for wood samples (a) untreated and treated with (b) S, (c) S/G5, (d) S/G5/V2, (e) S/G5/ $\mathrm{N} 1$, (f) S/G5/N1/V1 and (g) S/G5/N1/V2 at $30 \% \mathrm{RH}$ and at $30{ }^{\circ} \mathrm{C}$

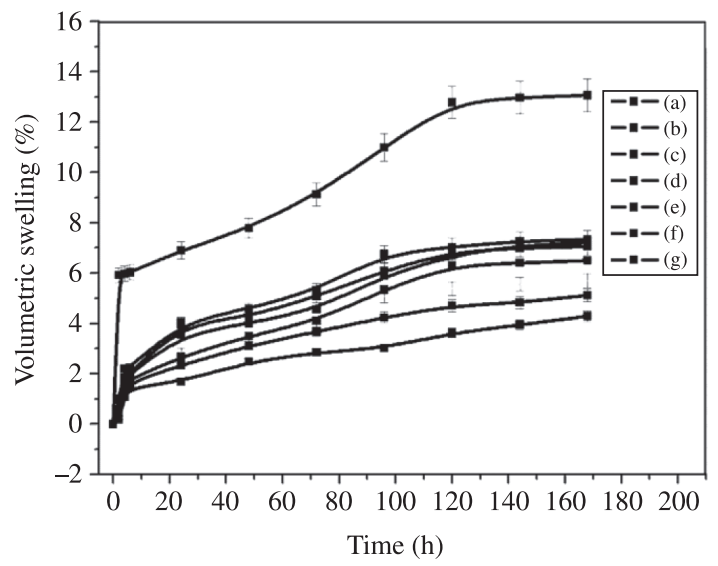

Figure 7. Volumetric swelling in water for wood samples (a) Untreated and treated with (b) S, (c) S/G5, (d) S/G5/V2, (e) S/G5/ $\mathrm{N} 1$, (f) S/G5/N1/V1 and (g) S/G5/N1/V2 at $30 \% \mathrm{RH}$ and at $30{ }^{\circ} \mathrm{C}$ 
Table 5. Anti- swelling efficiencies of wood polymer composites.

\begin{tabular}{ccccccc}
\hline Time $(\mathbf{h})$ & $\mathbf{S}$ & S/G5 & S/G5/V2 & S/G5/N1 & S/G5/N1/V1 & S/G5/N1/V2 \\
\hline 2 & 81.86 & 83.55 & 88.64 & 91.69 & 96.10 & 96.94 \\
4 & 83.05 & 84.74 & 89.83 & 92.88 & 97.28 & 98.13 \\
6 & 84.06 & 85.76 & 90.84 & 93.89 & 98.30 & 99.15 \\
24 & 100.0 & 101.69 & 106.77 & 109.83 & 114.23 & 115.08 \\
48 & 114.57 & 116.27 & 121.35 & 124.40 & 128.81 & 129.66 \\
72 & 138.11 & 139.81 & 144.91 & 147.96 & 152.71 & 153.22 \\
96 & 168.98 & 170.67 & 175.76 & 178.81 & 183.22 & 184.07 \\
120 & 197.11 & 198.81 & 203.90 & 206.94 & 211.31 & 212.40 \\
144 & 203.22 & 204.91 & 210.00 & 213.05 & 217.45 & 218.30 \\
168 & 202.37 & 204.06 & 209.15 & 212.20 & 216.61 & 217.45 \\
\hline
\end{tabular}

\subsection{Dimensional stability test}

\subsubsection{Swelling in water vapour and liquid water}

The results showing the effect of swelling in water vapour for untreated and treated wood samples at $65 \% \mathrm{RH}$ and room temperature $\left(30{ }^{\circ} \mathrm{C}\right)$ for different time periods were shown in Figure 6.

Similarly, Figure 7 shows the effect of swelling in liquid water at room temperature for treated and untreated wood samples. As expected, wood treated with GMA and silane showed least swelling. The explanation was similar to that of discussed earlier.

\subsubsection{Anti swelling efficiency}

The results of anti swelling efficiency of wood samples are shown in Table 5. Anti swelling efficiency was found to increase with the increase of time. The anti swelling efficiency was more in the case of WPNC. Improvement in dimensional stability of wood composites over virgin wood sample might be due to the deposition of polymer and nanoclay into the void spaces of wood, which prevented the cell walls from shrinking in response to moisture loss. Nanoclay further increased the tortuous path for diffusion of water. Besides this, the polymer was less hygroscopic than wood, less water would be absorbed during humid conditions ${ }^{19}$.

The dimensional stability was further improved by addition of VTCS. VTCS could form crosslinks and thus reduced the shrinkage and swelling caused by the water and as a result dimensional stability would be improved. Treatment of Scots pine with a mixture of two alkoxysilanes increased the ASE was reported in the literature ${ }^{36}$. GMA treatment remarkably improved the anti-swell efficiency of styrene impregnated rubber wood ${ }^{2}$.

\section{References}

1. Li Y, Dong X, Liu Y, Li J and Wang F. Improvement of dimensional stability of wood via combination treatment: swelling with maleic anhydride and grafting with glycidyl methacrylate and methyl methacrylate. International Biodeterioration and Biodegradation. 2011; 65:1087-1094. http://dx.doi.org/10.1016/j.ibiod.2011.08.009

2. Devi RR and Maji TK. Preparation and Characterization of Wood/Styrene-Acrylonitrile Copolymer/MMT Nanocomposite.

\section{Conclusions}

The ultimate goal of impregnation of styrene acrylonitrile co-polymer and nanoclay into soft wood was to improve the properties of soft wood. Wood polymer nanocomposites were prepared by the treatment of styrene acrylonitrile copolymer/nanoclay-GMA intercalating mixture in presence of VTCS. FTIR study showed the incorporation of VTCS and nanoclay in the wood/SAN composite. XRD analysis indicated that VTCS did not affect the dispersion of nanoclay into the polymer. Water uptake, dimensional stability and mechanical properties were improved due to incorporation of VTCS with nanoclay. SEM study revealed the presence of nanoparticles into wood cell wall and wood lumen and improvement in adhesion between wood and polymer by incorporation of VTCS. The uniform distribution of silicate layers of nanoclay in the WPC was studied by TEM. TGA and LOI study showed that thermal stability and flame retardant properties of wood polymer nanocomposites were improved due to incorporation of small amounts of VTCS with nanoclay.

From this work, it has been shown that styrene acrylonitrile co-polymer, nanoclay, GMA and VTCS are promising materials for the improvement of the soft wood performance and so, further studies to this direction are worthwhile.

\section{Acknowledgements}

One of the authors Rashmi R. Devi would like to express gratitude and thanks to Council for Scientific and Industrial Research, India for financial support in the form of Senior Research Fellowship (Grant in aid for CSIR No.09/796/ (0037)/2012/EMR-1).
Journal of Applied Polymer Science. 2011; 122:2099-2109. http://dx.doi.org/10.1002/app.34291

3. Sereshti H and Rovshandeh JM. Chemical Modification of Beech Wood. Iranian Polymer Journal. 2003; 12:15-20.

4. Stolf DO and Rocco Lah FA. Wood-Polymer Composite: Physical and Mechanical Properties of Some Wood Species Impregnated with Styrene and Methyl Methacrylate. Materials Research. 2004; 7(4): 611-617. http://dx.doi.org/10.1590/ S1516-14392004000400015 
5. Rowell RM. Chemical modification of wood. In: Rowel RM, editor. Handbook of Wood Chemistry \& Wood Composites. Washington: Taylor and Francis, CRC Press; 2005.

6. Islam MS, Hamdan S, Jusoh I, Rahman MR and Talib ZA. Dimensional Stability and Dynamic Young's Modulus of Tropical Light Hardwood Chemically Treated with Methyl Methacrylate in Combination with Hexamethylene Diisocyanate Cross-Linker. Industrial and Engineering Chemistry Research. 2011; 50:3900-3906. http://dx.doi. org/10.1021/ie1021859

7. Rozman HD, Kumar R, Abusamah A and Saad MJJ. Rubberwood-Polymer Composites Based on Glycidyl Methacrylate and Diallyl Phthalate. Journal of Applied Polymer Science. 1998; 67:1221-1226. http://dx.doi.org/10.1002/ (SICI)1097-4628(19980214)67:7<1221::AID-APP9>3.0.CO;2-I

8. Cai X, Riedl B, Zhang SY and Wan H. The impact of the nature of nanofillers on the performance of wood polymer nanocomposites. Composites Part A. 2008; 39:727-738. http:// dx.doi.org/10.1016/j.compositesa.2008.02.004

9. Zhao G and Lu WH. Structure and characterization of Chinese fir (Cunninghamia lanceolata) wood/MMT intercalation nanocomposite (WMNC). Frontiers Forests in China. 2008; 3:121126. http://dx.doi.org/10.1007/s11461-008-0020-0

10. Le BM, Wilkie $\mathrm{C}$, Bourbigot $\mathrm{S}$ and Duquesne S. Fire retardancy of polymers: the use of micro- and nano-sized mineral fillers. Cambridge: R.S.C.; 2004.

11. Li B and He JM. Investigation of mechanical property, flame retardancy and thermal degradation of LLDPEwood-fibre composites. Polymer Degradation and Stability. 2004; 83:241-246. http://dx.doi.org/10.1016/S01413910(03)00268-4

12. Mahmoud AA, Eissa AMF, Omar MS, Etsawy AA and Shaaban AF. Improvement of White Pinewood Properties by Impregnation with Thiourea-Formaldehyde Resin and Orthophosphoric Acid. Journal of Applied Polymer Science. 2000; 77:390397. http://dx.doi.org/10.1002/(S ICI) 1097 4628(20000711)77:2<390::AID-APP16>3.0.CO;2-C

13. Hamdani S, Longuet C, Perrin D, Lopez-cuesta JM and Ganachaud F. Flame retardancy of silicone-based materials. Polymer Degradation and Stability. 2009; 77:465-495. http:// dx.doi.org/10.1016/j.polymdegradstab.2008.11.019

14. Donath S, Militz H and Mai C. Wood modification with alkoxysilanes. Wood Science and Technology. 2004; 38:555566. http://dx.doi.org/10.1007/s00226-004-0257-1

15. Boonkrai S and Aht-Ong D. Effect of 3-Aminopropyltrimethoxysilane-g-Rice Husk Silica on Flame Retardant of ABS/Organomontmorillonite Nanocomposites. Advances in Material Research. 2010; 93-94:91-94. http:// dx.doi.org/10.4028/www.scientific.net/AMR.93-94.91

16. Devi RR and Maji TK. Chemical modification of simul wood with styrene-acrylonitrile copolymer and organically modified nanoclay. Wood Science and Technology. 2012; 46:299-315. http://dx.doi.org/10.1007/s00226-011-0406-2

17. Liu D, Padias AB and Hall HK Jr. On the Thermal CoPolymerization of Styrene with Acrylonitrile. Macromolecules 1995; 28(2):622-626. http://dx.doi.org/10.1021/ ma00106a030

18. Spurr AR. A low-viscosity epoxy resin embedding medium for electron microscopy. Journal of Ultrastructural Research. 1969; 6:31-43. http://dx.doi.org/10.1016/S00225320(69)90033-1

19. Devi RR and Maji TK. Physical properties of simul (red-silk cotton) wood (Bombax ceiba L.) chemically modified with styrene acrylonitrile co-polymer and nanoclay. Holzforschung. 2011; 66(3):365-371.

20. American Society for Testing and Materials - ASTM. Standard D 570-99: Standard test methods for water absorption of plastics: annual book of ASTM Standard. ASTM International; 2002.

21. Devi RR, Maji TK and Banerjee AN. Studies on Dimensional stability and Thermal properties of Rubber wood chemically modified with Styrene and Glyidyl Methacrylate Journal of Applied Polymer Science. 2004; 93:1938-1945.

22. Devi RR and Maji TK. Effect of Nano-ZnO on Thermal, Mechanical, UV Stability, and Other Physical Properties of Wood Polymer Composites. Industrial and Engineering Chemistry Research. 2012; 51:3870-3880. http://dx.doi. org/10.1021/ie2018383

23. Devi RR and Maji TK. Chemical Modification of Rubber Wood with Styrene and Glycidyl Methacrylate. Journal of Applied Polymer Science. 2008; 29:1258-1262.

24. Shane BE, Gary RD and Loo TN. Effects of coupling agent on the physical properties of wood-polymer composites. Journal of Material Processing Technology. 1995; 48:365-372. http:// dx.doi.org/10.1016/0924-0136(94)01670-V

25. Yap MGS, Que YT and Chia LH. FTIR Characterization of Tropical Wood-polymer composites Journal of Applied Polymer Science. 1991; 43:2087-2090.

26. Shen S, Guirgis GA and James RD. Spectra and structure of silicon-containing compounds. XXVIII1 Infrared and Raman spectra, vibrational assignment, and ab initio calculations of vibrational spectrum and structural parameters of vinyltrichlorosilane. Structural Chemistry. 2001; 12:33-43. http://dx.doi.org/10.1023/A:1009258017813

27. Rahman WA, Adenan N, Ali RR and Sulaiman H. Effect of silane cross linker on the thermal properties of Rice straw/HDPE biocomposite. Journal of Applied Science. 2009; 9: 3041-3047. http://dx.doi.org/10.3923/jas.2009.3041.3047

28. Lu WH, Zhao GJ and Xue JH. Preparation and characterization of wood/montmorillonite nanocomposites. Forestry Studies in China. 2006; 8:35-40. http://dx.doi.org/10.1007/s11632006-0007-6

29. Zimmermann T. Cellulose fibrils in wood cell Walls and their potential for Technical applications. [Dissertation]. Zurich: University of Hamburg; 2007.

30. Ismail H, Shuhelmy SS and Edyham MR. The Effects of a Silane Coupling Agent on Curing Characteristics and Mechanical Properties of Bamboo Fibre filled natural rubber composites. European Polymer Journal. 2002; 38:39-47. http:// dx.doi.org/10.1016/S0014-3057(01)00113-6

31. Devi RR and Maji TK. Effect of Glycidyl Methacrylate on the Physical Properties of Wood-Polymer Composites. Polymer Composites. 2007; 28:1-5. http://dx.doi.org/10.1002/pc.20265

32. Das G and Karak N. Vegetable oil-based flame retardant epoxy/clay nanocomposites. Polymer Degradation and Stability. 2009; 94:1948-1954. http://dx.doi.org/10.1016/j. polymdegradstab.2009.07.028

33. Laoutid F, Bonnaud L, Alexandre M, Lopez-Cuesta JM and Dubois P. New prospects in flame retardant polymer materials: from fundamentals to nanocomposites. Material Science and Engineering $R$ : Reports. 2009; 63:100-125. http://dx.doi. org/10.1016/j.mser.2008.09.002

34. Powell CE and Gary WB. Physical Properties of Polymer/Clay Nanocomposites. In: James ME, editors. Physical Properties of Polymers Handbook. 2nd edn. Germany: Springer; 2007. part VI, p. 561-575.

35. Giudice CA and Pereyra AM. Fire Resistance of Wood Impregnated with Soluble Alkaline Silicates. Research letters in Materials Science. 2007; ID 3195664.

36. Panov D and Terzeiv N. Study on some alkoxysilanes used for hydrophobation and protection of wood against decay. International Biodeterioration and Biodegradation. 2009; 63:456-461. http://dx.doi.org/10.1016/j. ibiod.2008.12.003 